\title{
Podem os Municipios, no Estado de São Paulo, regulamentar o exercicio de profissões?
}

A Camara Municipal de S. Paulo tem regulamentado o exercicio, no municipio, de varias profissões, como as de constructor, electricista, encanador, empregados domesticos, etc. Em alguns casos, essa regulamentação tem sido de incontestavel utilidade. Em outros, acarretou inconvenientes graves. Assim é que a lei municipal 2986, de 1926 , introduziu, no seu art. $4 .^{\circ}$, normas contrarias, relativamente a construcções, ás constantes da lei estadoal n. ${ }^{\circ}$ 2022 , de 1924, estabelecendo uma categoria nova de profissionaes não contemplada nesta ultima. Por essa forma o municipio procurou, embora inconscientemente, talvez, condicionar no seu territorio a vigencia da lei do Estado...

Respondendo a uma consulta tivemos occasião de declarar que, em nossa opinião, fallece aos municipios paulistas competencia para regulamentar profissões.

$\mathrm{O}$ assumpto não é desinteressante, e agora cuidamos de justificar aquelle ponto de vista.

\section{***}

Não se trata de discutir, aqui, a possibilidade de regulamentação, pelo poder publico, do exercicio das varias profissões. E' pacifico, em doutrina, que a regulamentação em nada prejudica o principio consagrado no art. 72 . $\$ 24$, da Constituição Federal. Ella decorre do poder de 
policia administrativa, imposto pela salvaguarda de interesses publicos de grande monta. A liberdade constitucional só pode ser entendida como possibilidade, para todos os individuos, de escolher o ramo de sua actividade, com absoluta inexistencia de privilegios de casta. O que o poder publico exige do individuo que quer exercer determinada profissão é, unicamente, a prova da habilitação profissional.

A questão focalizada é apenas a de saber se aquella regulamentação compete, entre nós, á União, ao Estado, ao Municipio, ou, simultaneamente, a mais de uma dessas entidades. Na ultima hypothese, seria necessario indagar dos limites da competencia cumulativa.

E' preciso distinguir, preliminarmente, a regulamentação do exercicio das profissões da regulamentação do trabalho.

A primeira consiste na exigencia de titulos de habilitação profissional, com requisitos de validade, acompanhada de formalidades de exhibição, registro, etc.

A segunda se refere á determinação dos preceitos que devem presidir ao exercicio effectivo do trabalho, em geral tendo em vista os interesses de saúde, hygiene e segurança, tanto em relação ao trabalhador como ao publico, e abrange, actualmente, varias questões sociaes.

A regulamentação do exercicio das profissões não compete, no Brasil, á União, por lhe não ter sido attribuida. A União só tem os poderes que o pacto constitucional expressamente lhe outorga.

A solução seria differente se se tratasse da regulamentação do irabalho, porquanto, desde a reforma censtitucional de 1926, a União passou a ter competencia para legislar sobre elle. (Art. 34 n. ${ }^{\circ} 28$ ). E, note-se de passagem, essa competencia se tornou exclusiva, em razão de um erro technico dos reformadores, que incluiram o inciso no art. 34, quando o seu pensamento era o de o collocar no art. 35. 
Quanto aos Estados, não pode ser posta em duvida sua competencia para regulamentar o exercicio das profissões, á vista do disposto no art. 65 , n. ${ }^{\circ} 2$, da Constituição Federal.

Resta saber se, no Estado de S. Paulo, tal competencia teria passado, mesmo dentro de certos limites, aos municipios.

Aqui se torna necessaria rapida digressão sobre a natureza dos poderes municipaes.

\section{洋}

No direito publico de alguns paizes, tem-se reconhecido, aos municipios, duas ordens de poderes. De um lado, poderes proprios, decorrentes de sua personalidade e essencia. De outro lado poderes que o Estado lhes delega.

Esse ponto de vista prevaleceu, exemplificativamente, na lei francesa de 14 de dezembro de 1789 , na Constituição Belga de 7 de fevereiro de 1831, nas leis austriacas de 17 de março de 1849 e de 5 de março de 1862.

Sobre discussão do assumpto podem vêr-se GIRON, Le Droit Public de la Belgique, pg. 160; Belt Jens, La Constituition Belge Revisée, pg. 339; ORBAN, Le Droit Const. de la Belgique, 1906, vol. I, pg. 396; ULBRICH, Lehrbuch des oesíerreichischen Verwaltungsrechtes, 1903, pg. 127. BRoCKHAUSEn, Die oesterreichische Gemeindeordnung, 1905 , pgs. 8 a 38 e 119.

Em torno do presupposto de poderes attinentes, por direito proprio, ao municipio, gyrou, por muito tempo, o problema de descentralização administrativa, como explica Bórsi (Le funzioni del Comune Italiano, no Tratado, de ORLANDO, vol. 2 , parte $2 .^{a}$., pg. 427)

Predomina hoje, entretanto, a opinião de que as funcções municipaes derivam todas de delegação. O criterio. do interesse local e peculiar se applica, apenas, como um 
limitativo da extensão funccional, sempre, porem, dentro de competencias que são, quanto aos varios assumptos, delegadas ao municipio.

Esta maneira de encarar a questão começou a prevalecer depois que GNEIST, com seus luminosos estudos sobre o governo local na Inglaterra, demonstrou que este não se fundava sobre direito proprio das communas, (que erroneamente tinham sido consideradas como contrapostas ao Estado), mas ficava sempre dependendo da vontade e da actividade do poder central. (Vide GNEIST, Selfgovernment in England; Englisches Verwaltungsrecht; VAUTHIER, Il governo locale dell'Inghilterra; BERTOLINI, Il governo locale inglese; HATSCHEK, Englisches Staastsrecht)

A theoria da delegação foi consagrada na Italia, em termos que podemos considerar absolutos, depois de um debate parlamentar em que o assumpto foi discutido sob todas as suas faces.

Em doutrina tambem domina, de forma incontrastavel, o que autorizou a affirmação de BORSI:

"Sotto l'aspetto giuridico, tutte le funzioni del Comune moderno procedono da una assegnazione dello Stato." (Op. cit., pg. 430)

A thoria opposta, das funcções de direito proprio, pode hoje apenas contribuir, com os criterios que apresenta, para esclarecimentos, inspirando as delegações que os Estados façam aos municipios. Poucos são os autores que, como MARCHI (L'istituto giuridico dell'autarchia, pg. 286), the attribuem maior força.

Nos Estados Unidos os municipios só têem poderes de delegação, - o que é importante ter em vista, pela affinidade existente entre o direito publico norte americano e o brasileiro. Alguns autores, reconhecendo sempre só existir a delegação, distinguem, entretanto, naquelle paiz, a delegação expressa da tacita. Reflexamente, essa distincção veio produzir argumentos em favor da theoria dos poderes 
de direito proprio, cujos partidarios entraram a buscar uma correspondencia entre aquelles poderes e os da delegação tacita.

Outros, como BRYCE, declaram que os municipios têm funcções principaes, que chamam delegadas, e funcções secundarias consistentes em execução de medidas contidas em leis do Estado, e no exercicio de funcções materiaes, como limpeza das ruas. (La Republique Americaine, 1901, vol. 2, pg. 298)

E' facil, porém, identificar as funcções secundarias, a que allude BRYCE, com as funcções da delegação tacita, donde se conclue que, afinal, em theoria, só se reconhecem aos municipios poderes delegados, nos Estados Unidos.

$$
\text { ** }
$$

Teria sido, no Brasil, acceito o principio das attribuições municipaes por direito proprio, ou, ao contrario, o principio das attribuições sempre resultantes de mera delegação?

Temos que procurar a solução no art. 68 da Constituição Federal, que dispõe:

"Os Estados organizar-se-ão de forma que fique assegurada a autonomia dos municipios, em tudo quanto respeite ao seu peculiar interesse"

Technicamente defeituoso, esse texto da Constituição englobou no mesmo preceito, confundindo-as, noções differentes.

Consagrou a autonomia do municipio. Mas, tomando a palavra "autonomia" no sentido popular, e não no sentido technico, vinculou a respectiva noção á regra do peculiar interesse, que limita, genericamente, a actividade municipal, e que não se refere á questão da autonomia, mas á da descentralização administrativa.

Autonomia, na technica do direito publico, quer dizer apenas governo proprio, isto é, provimento proprio dos 
cargos da governação municipal. Autonomo é o municipio que faz, independentemente do apparelhamento governativo do Estado, aquelle provimento. Não autonomo é o municipio cujas autoridades são nomeadas pelo governo geral.

Autonomia, pois, nada tem que vêr com interesses peculiares. ORLANDO, com a habitual clareza, põe essa questão nos devidos termos. (Principii di Diritto Administrativo, n. 258 e segs.)

O problema que, no momento, nos interessa, em face do art. 68 da Constituição Federal, é o da descentralização, e não o da autonomia.

Ora, embora vinculando-a erroneamente á noção de autonomia, é certo que aquelle texto consagrou a regra do peculiar interesse, relativa á descentralização.

Essa regra, em theoria, é limitativa, isto é, não importa na indicação das funç̧ões attribuiveis á administração municipal. Serve apenas para determinar até onde deve ser respeitada a competencia communal, dentro dos assumptos que, pela delegação, the forem confiados.

Mas, no art. 68 da Constituição, o principio do interesse peculiar apparece com significado differente, que não é o technico, pois que vem alliado á idéa de autonomia, e acompanhado da expressão "em tudo quanto respeite"

$A^{\prime}$ vista dessas circunstancias, é possivel, aos descentralizadores, entender que aquella clausula se impoz como indicativa, em termos geraes, da competencia funccional do municipio, de maneira a obrigar os Estados, na sua organização, a reconhecer um minimo irreductivel de poderes municipaes independentemente de qualquer delegação expressa.

O conteúdo desse minimo só pode ser especificado, no direiio constituido, pelo exame das varias legislações estadoaes. De facto, os legisladores dos Estados-membros da federação são os interpretes forçados da clausula "interesses peculiares" do art. $68 \mathrm{em}$ se tratando da investigação do direito constituido. 
A Constituição do Estado de S. Paulo não reconheceu aos municipios qualquer attribuição das chamadas de direito proprio, mas, dando ao congresso do Estado competencia para legislar sobre o regimen municipal, (art. 24, n. ${ }^{\circ} 18$, letra $f$ ), repetiu, como restriç̧ão imposta á legislação ordinaria, o preceito do art. 68 da Constituição Federal. (Art. 57).

A legislação ordinaria do Estado enumerou as attribuições dos municipios. Não o fez, entretanto, taxativamente, pois incluio, entre os itens da enumeração, um inciso de attribuições genericas, com intuito, talvez, de obedecer á resalva constitucional.

Resta saber se, no inciso generico, ficaria incluida competencia para regulamentar o exercicio das profissões, porquanto, delegação expressa, não existe, nesse sentido.

O mencionado inciso dispõe:

"Tudo quanto respeita á policia e ao bem do municipio, que não estiver provido por lei do Estado" (Lei 1038, de 1906, art. 18, n. ${ }^{\circ} 16$; Dec. 1533, de 1907, art. 32, n. ${ }^{\circ} 16$ )

Em primeiro lugar, esse inciso generico, unico existente na legislação do Estado, não se refere, nem se pode referir, ao "minimo irreductivel de attribuições", que os partidarios da theoria dos poderes de direito proprio poderiam alicerçar no art. 68 da Constituição. Se nelle se tratasse do minimo irreductivel, a competencia seria municipal, em qualquer caso, e não apenas quando o assumpto "não estiver provido por lei do Estado"

Em segundo lugar, e qualquer que fosse o significado theorico do inciso, a expressão "tudo quanto respeita á policia e ao bem do municipio" viria excluir, por si, a hypothese da regulamentação das profissões, a qual é, sem duvida, attinente ao interesse geral, e não ao local. Não se comprehende que individuos, exercendo profissão dentro de um municipio, e inhabilitados para a exercer fóra delle, limitem os effeitos do seu campo de acção ás fronteiras com- 
munaes. Esses effeitos se reflectiriam, frequentes vezes, fóra dellas, sem que para isso o profissional do municipio se deslocasse.

Mesmo, porem, que, por absurdo, se admittisse que a clausula generica supra transcripta se refere ao minimo irreductivel de attribuições, ter-se-ia que concordar em que, no dito minimo, não se inclue a attribuição de regulamentar profissões. Esta, em theoria, pertence sempre ao Estado, e não aos municipios, por ser referente a interesse geral.

Dessa forma têm pensado, sem duvida, os legisladores dos varios Estados, no Brasil. Tanto assim que, nos dois unicos Estados em que os municipios, contrariamente aos principios theoricos, receberam aquella attribuição, ella derivou de delegação expressa, e não se subentendeu como de delegação tacita, nem como poder de direito proprio. (Vide Lei pernambucana, n. ${ }^{\circ} 1733$, de 26 de Maio de 1925, art. $19, n .^{\circ} \mathrm{XV}$, e Lei cearense, n. ${ }^{\circ} 39$, de 10 de Novembro de 1892 , art. 25, n. $^{\circ}$ XXVIII)

Do exposto se conclue que os municipios, no Estado de São Paulo, não podem regulamentar o exercicio de profissões.

Essa conclusão perfeitamente se coaduna com os principios theoricos que regem a materia.

Dr. Mario Masagão.

(Livre Docente de Dircito Administrativo) 